\title{
DIGNIDADE HUMANA E DIREITOS REAIS SOCIAIS: INSTRUMENTOS DE EFETIVIDADE À MORADIA E DEMAIS INTERESSES SOCIAIS
}

\author{
Adriano Stanley Rocha Souza ${ }^{1}$ \\ Camila Bottaro Sales ${ }^{2}$
}

\section{Resumo}

O presente trabalho aborda os novos direitos reais instituídos pela Lei $\mathrm{n}^{\circ} 11.481$ de 31 de maio de 2007 que acrescentou ao rol taxativo do artigo 1.225 do Código Civil a concessão de uso especial para fins de moradia e a concessão do direito real de uso que objetivam concretizar direitos fundamentais tão importantes à nossa Constituição. Iniciou-se por uma análise da definição de um conteúdo mínimo de acesso à moradia com respeito à questão da dignidade humana. Em seguida, tratou-se do estudo didático dos direitos reais em tela, considerando o seu estudo atrelado à importância dos direitos fundamentais. A partir da análise das principais características dos novos institutos, evoca-se um instrumento de efetividade à moradia e outros direitos sociais.

Palavras-chave: Direitos fundamentais; Direito à moradia; Dignidade humana; Direito privado; Concessão de uso especial para fins de moradia; Concessão de direito real de uso.

\section{INTRODUÇÃO}

Ao iniciarmos o estudo das principais características dos Direitos Reais, analisamos, dentre outras, a característica da tipicidade ou o princípio dos numerus clausus. Sendo assim, concluímos pela taxatividade do artigo 1.225 do Código Civil, ou seja, somente ao Poder

1 Graduação em Direito pela Pontifícia Universidade Católica de Minas Gerais (1996), Mestrado em Direito pela Pontifícia Universidade Católica de Minas Gerais (1999), Doutorado em Direito pela Pontifícia Universidade Católica de Minas Gerais (2003) e Pós-doutorado pela Pontifícia Universidade Católica do Paraná. Cursou disciplinas isoladas no Programa de Doutorado da Universidad de Deusto, em Bilbao (Espanha). Atualmente é professor Adjunto III da Pontifícia Universidade Católica de Minas Gerais, colaborador da Escola Superior de Advocacia - OAB/MG. O professor é orientador de diversos projetos de iniciação científica da PUCMINAS e coordenador do projeto de extensão, naquela mesma instituição, denominado "Cidadania no Beira Linha". Autor de vários artigos jurídicos, capítulos de livros e dos Livros "Direito das Coisas" (manual integrante da Coleção Direito Civil da Editora Del Rey), e "Tutelas de Urgência na Reparação do Dano Moral". Tem experiência na área de Direito, com ênfase em Direito Civil, atuando principalmente nos seguintes temas: direito civil, propriedade, responsabilidade civil, dano moral e meio ambiente.

2 Graduada em Direito pela Pontifícia Universidade Católica de Minas Gerais (2005), Especialista em Direito de Família e Sucessões pelo Instituto de Educação Continuada da PUC-Minas (2006). Mestra em Direito Privado pela Pontifícia Universidade Católica de Minas Gerais (2008-2010). Atuou como: Advogada - Carvalho e Gontijo Advocacia e Consultoria, pesquisadora de Mediação do Instituto Brasileiro de Direito de Família, conciliadora do Juizado de Conciliação, professora da Faculdade de Direito Unipac - Itabirito e Mariana das disciplinas: Direito Civil, Direito Processual Civil, Prática Jurídica, Direito Administrativo e Direito Empresarial, coordenadora do Núcleo de Prática Jurídica - NPJ - da Faculdade Presidente Antônio Carlos Itabirito, coordenadora do Grupo de Estudos da Secretaria de Urbanismo, do Conselho Tutelar e do Setor de Mediação do NPJ, professora do curso de Pós-graduação em Orçamento e Gestão Pública da Faculdade Presidente Antônio Carlos de Itabirito da disciplina: Direito Público e Constitucional, componente do Núcleo Docente Estruturante - NDE- da Faculdade Presidente Antônio Carlos de Itabirito e Mariana. Atualmente é

Revista da Faculdade Mineira de Direito, v.13, n. 25, jan./jun. 2010 - ISSN 1808-9429. 83 
Legislativo cabe a criação de novos direitos reais e sua regulamentação. Não cabe ao particular tal prerrogativa.

Neste sentido e atendendo a este princípio é que a Lei $\mathrm{n}^{\circ} 11.481$ de 31 de maio de 2007, que prevê medidas voltadas aos interesses sociais, no seu artigo 10 acrescentou dois novos incisos no artigo 1225 do Código Civil que passou a vigorar com a seguinte redação:

\author{
Art. 1225. São direitos reais: [...] \\ XI- a concessão de uso especial para fins de moradia; \\ XII- a concessão de direito real de uso.
}

Podemos dizer que o estudo dos novos Direitos Reais, os chamados Diretos Reais Sociais perpassam por uma análise interdisciplinar que abrange não só o ramo do Direito Civil, como do Direito Administrativo, do Direito Constitucional e dos Direitos Humanos, uma vez que as concessões se concretizam em imóveis públicos em prol de interesses socialmente relevantes previstos na Carta Maior.

Como reflexo dos novos paradigmas do Direito Civil que passou a ser interpretado à luz da Constituição da República de 1988 (CR/88) - fenômeno conhecido como constitucionalização do Direito Civil - a Lei $\mathrm{n}^{\circ} 11.481$ vem concretizar princípios como o dignidade humana, da função social da propriedade e da solidariedade operacionalizando o direito à moradia previsto no artigo $6^{\circ}$ da $\mathrm{CR} / 88$ e demais direitos fundamentais inscritos no artigo $5^{\circ}$, ainda que para isso faça uso de bens públicos.

Desta forma, para um a compreensão mais detalhada dos novos direitos reais nos paradigmas do Estado Democrático de Direito, pertinente se faz uma análise contextualizada do direito à moradia para seguirmos o estudo pontual de cada um destes novos institutos.

\title{
2. O ACESSO À MORADIA COMO FUNDAMENTO DA DIGNIDADE HUMANA
}

A ordem jurídica atual condiciona o estudo dos direitos fundamentais atrelados ao princípio da dignidade humana, se compreendermos direitos fundamentais como sendo situações jurídicas que visam concretizar garantias de convivência digna sem as quais os homens não se realizariam. Segundo José Afonso da Silva (2006, p. 182): “A dignidade da pessoa humana indica o valor supremo que atrai o conteúdo de todos os Direitos Fundamentais do Homem".

Professora das Instituições: Centro Universitário do Distrito Federal- UDF, Centro Universitário de BrasíliaUniceub e IESB- Oeste no Distrito Federal.

Revista da Faculdade Mineira de Direito, v.13, n. 25, jan./jun. 2010 - ISSN 1808-9429. 84 
Neste sentido, o mesmo autor divide os direitos fundamentais em cinco categorias: $1^{\text {a }}$ ) direitos individuais, $2^{\mathrm{a}}$ ) direitos coletivos, $3^{\mathrm{a}}$ ) direitos sociais, $4^{\mathrm{a}}$ ) direitos à nacionalidade, $5^{\mathrm{a}}$ ) direitos políticos.

No ordenamento nacional, o direito à moradia foi inserido na Carta Maior como direito social com a Emenda Constitucional nº 26/00.

$\mathrm{Na}$ seara internacional, o Pacto Internacional dos Direitos Econômicos, Sociais e Culturais, adotado pela Resolução $n^{\circ}$ 2.200- A (XXI) da Assembléia Geral das Nações Unidas, em 16 de dezembro de 1966 e ratificado pelo Brasil em 24 de janeiro de 1992, determina no artigo 11 que:

Os Estados-partes no presente Pacto reconhecem o direito de toda pessoa a um nível de vida adequado para si próprio e para sua família, inclusive alimentação, vestimenta e moradia adequadas, assim como uma melhora contínua de suas condições de vida.

O conteúdo do direito á moradia significa basicamente "habitar" e seu escopo definitivo é a proteção de um direito fundamental da pessoa humana.

Conforme leciona José Afonso da Silva, o direito à moradia não significa necessariamente ser proprietário; mas habitar num local que possua condições que preservam a integridade do ser humano em toda sua completude.

Portanto, é dever do Estado fornecer instrumentos que efetivem o direito à moradia na maior medida possível.

No livro III da parte especial do Código Civil - Direito das Coisas -, analisando o artigo 1.225 que traz o rol dos direitos reais, observamos no inciso primeiro a inserção do direito real mais amplo que trata-se do direito de propriedade. Aliás, seu estudo sistematizado no Código Civil se justifica frente a ordem constitucional que não apenas institui o direito de propriedade, mas o eleva à qualidade de direito fundamental desde que atenda a sua função social (artigo $5^{\circ}$, XXIII CR/88).

Além da propriedade outros direitos reais foram inseridos no ordenamento juscivilista com o objetivo que concretizar o direito à moradia. $\mathrm{O}$ direito real de habitação, por exemplo, garante o direito temporário à alguém de residir gratuitamente em imóvel alheio, considerando que este imóvel é de natureza particular.

No dia 31 de maio de 2007 foi promulgada a Lei $n^{\circ} 11.481$ que trata de medidas voltadas à regularização fundiária de interesse social em imóveis da União. Foi acrescentado ao rol do artigo 1.225 do Código Civil, dois novos direitos reais: a concessão de uso especial para fins de moradia e a concessão de direito real de uso.

Revista da Faculdade Mineira de Direito, v.13, n. 25, jan./jun. 2010 - ISSN 1808-9429. 85 
A primeira modalidade de concessão trata-se de mais uma forma encontrada pelo legislador de efetivação do direito social à moradia que garante à população de baixa renda, preenchidos determinados requisitos, o direito de habitar gratuitamente em imóveis públicos, especialmente imóveis da União.

A segunda modalidade de concessão garante a concretização de demais direitos de interesses sociais, como a saúde, à educação e a cultura que fazem parte do alicerce sob o qual se baseia os direitos fundamentais.

Sendo assim, passamos analisar cuidadosamente os novos direitos reais e sua importância nas chamadas situações jurídicas de natureza privadas.

\section{A CONCESSÃO DE USO ESPECIAL PARA FINS DE MORADIA}

A concessão de uso especial para fins de moradia, primeiramente, estava prevista no Estatuto da Cidade (Lei ${ }^{\circ} 10.257 / 01$ ) que regularia esta nova modalidade de direito real nos seus artigos 15 a 20. Tais artigos foram vetados pelo então Presidente da República, Fernando Henrique Cardoso, por motivos de "interesse público".

A concessão foi então instituída, dois meses após a promulgação do Estatuto da Cidade, pela Medida Provisória (MP) n 2.220, de 04 de setembro de 2001 como instrumento de política urbana cujo objetivo é a concretização do direito social à mordia, mínimo necessário a sobrevivência digna de qualquer ser humano, com intuito de solucionar o problema das ocupações irregulares que ocorreram de forma desordenada durante décadas.

Desta forma, a Lei $\mathrm{n}^{\circ}$ 11.481/07, regulamentou então, a MP n ${ }^{\circ} 2.220 / 01$ acrescentando a concessão de uso especial para fins de moradia ao rol dos direitos reais contidos no artigo 1.225 do Código Civil.

Podemos dizer que a concessão de uso especial para fins de moradia é um direito real social instituído por ato administrativo denominado concessão. Segundo a administrativista, Maria Silvia Zanella Di Pietro (2005, p. 605), “concessão é o contrato administrativo pelo qual a Administração Pública faculta ao particular a utilização privativa de bem público, para que se exerça conforme a sua destinação”.

Seu objetivo específico é conceder moradia à população de baixa renda sobre as áreas de propriedade da União, preenchido os requisitos da MP $\mathrm{n}^{\circ} 2.220 / 01$, que passaremos a analisá-los agora. 


\subsection{Requisitos}

A MP $n^{\circ} 2.220 / 01$ regulamenta a concessão de uso que trata o artigo $183, \S 1^{\circ}$ da $\mathrm{CR} / 88$. Vale ainda ressaltar, que a Lei $\mathrm{n}^{\circ} 11.481$ trouxe para o nosso ordenamento jurídico a concessão de uso especial para fins de moradia, mas seus requisitos são encontrados ainda na MP por determinação da própria lei:

\footnotetext{
A concessão de uso especial para fins de moradia aplica-se às áreas de propriedade da União, inclusive aos terrenos de marinha e acrescidos, e será conferida aos possuidores ou ocupantes que preencham os requisitos legais estabelecidos na Medida Provisória n ${ }^{\text {2 } 220, ~ d e ~} 04$ de setembro de 2001.
}

Os requisitos se assemelham aos da usucapião constitucional, mas são institutos distintos. De acordo com o artigo $1^{\circ}$ da $\mathrm{MP}$, tem direito à concessão de uso especial para fins de moradia:

$1^{\circ}$ ) Aquele que até 30 de junho de 2001 possuiu por 05 anos imóvel público da União (inclusive da marinha) de até 250 metros em área urbana de forma ininterrupta e contínua.

$2^{\circ}$ ) Cujo objetivo é garantir o direito à moradia. Esta nova modalidade de direitos reais somente se aplica se a finalidade do uso é para moradia da pessoa ou de sua família, de forma gratuita.

$3^{\circ}$ ) O concessionário não poderá ser proprietário de outro imóvel, seja ele urbano ou rural. Conforme determina a MP, este direito será reconhecido uma única vez.

$\mathrm{O}$ intuito inovador da lei que visa garantir o direito social à mordia, ainda que instituído em imóveis públicos (de todos os cidadãos), se justifica frente ao interesse do particular, uma vez que garante a definição de um conteúdo mínimo do direito à moradia.

Observa-se que a nova lei acaba por restringir grande parte de pessoas que se encontram em situações semelhantes, mas não preenchem o requisito temporal determinado no primeiro item, criando uma solução à uma parcela da população brasileira e deixando parte dela privada deste direito.

\subsection{Características}

A MP ainda prevê que o novo direito real poderá ser transmitido inter vivos ou causa mortis. Pode o herdeiro legítimo continuar na posse do seu antecessor, desde que, da abertura da sucessão já cumpra o requisito de habitação no imóvel.

A concessão de uso especial para fins de moradia poderá ser concedida ao homem e a mulher, independente do estado civil e, como já dito, uma única vez. 
Interessante analisarmos que o Poder Público poderá garantir a concessão de uso especial para fins de moradia em local diferente daquele onde a posse foi exercida, caso esta área acarrete risco à vida ou à saúde dos ocupantes ou tratar-se de área de uso comum do povo, destinada a projeto de urbanização, de interesse da defesa nacional, da preservação ambiental e da proteção dos ecossistemas naturais, e ainda, aqueles locais reservados à construção de represas e obras congêneres ou situado em via de comunicação.

\subsection{Modalidades}

Podemos dizer que a MP trouxe duas formas especiais deste novo direito real. Seria a concessão "coletiva" de uso especial para fins de moradia e a concessão de uso especial para fins comerciais.

No primeiro caso, preenchido os requisitos analisados acima, poderá o Poder Público conceder o uso para fins de moradia de forma coletiva, desde que os concessionários sejam pessoas de baixa renda, ocupem área superior a 250 metros, podendo ainda somar suas posses com as posses dos antecessores.

Neste caso, cada concessionário receberá uma fração ideal do terreno, podendo acordar frações diferentes. Contudo, cada possuidor não poderá receber uma fração superior a 250 metros.

Com relação à segunda forma especial, a MP determina que o Poder Público competente, preenchidos os requisitos legais, poderá conceder o uso para aqueles que possuírem área até 250 metros cuja finalidade seja comercial. Aplicam-se, neste caso, as demais características analisadas: gratuidade e acessão.

\subsection{Procedimento}

Primeiramente, a concessão de uso especial para fins de moradia será obtida através do ato da Administração Pública que concede direitos e poderes ao particular denominado concessão.

O pedido deverá ser instruído com a certidão do Poder Público informando a localização do imóvel em área urbana, bem como o objetivo determinado de moradia do requerente ou de sua família.

A administração pública deverá decidir em até 12 meses sobre o requerimento, e, na ocorrência de omissão, poderá o ocupante pleitear judicialmente, caso em que a concessão será declarada pelo juiz mediante sentença declaratória. 
Seja pela via administrativa ou judicial, o título deverá ser registrado no Cartório de Registro de Imóveis, conforme determina o artigo 167, I, 37 da Lei $n^{\circ}$ 6.015/73 - Lei de Registro Público.

\subsection{Extinção}

A MP relaciona duas formas de extinção da concessão de uso especial para fins de moradia:

a) Quando houver mudança da finalidade especificada na lei, ou seja, quando o concessionário ou sua família utilizar o imóvel com o objetivo diverso da moradia.

b) Se o concessionário tornar-se proprietário ou constituir nova concessão de imóvel urbano ou rural.

\section{A CONCESSÃO DE DIREITO REAL DE USO}

O segundo novo direito real acrescentado ao artigo 1.225 do Código Civil trata-se também de um direito real de cunho social que possui finalidade e requisitos diferentes da concessão analisada anteriormente.

A concessão de direito real de uso é o direito real que também ocorre por ato administrativo vinculado do Pode Público (concessão) que recai sobre imóveis de propriedade da União Federal, cujo objetivo não é determinado, mas deve-se atender interesses públicos ou sociais, bem como um aproveitamento de interesse nacional.

Essa nova modalidade de direito real foi instituída pelo Decreto-lei $\mathrm{n}^{\circ} 271$, de 28 de fevereiro de 1967, como nova redação dada pela Lei nº 11.481.

Segundo essa lei, a concessão de direito real de uso será deferida quando preencher os seguintes requisitos:

a) Alcançar terrenos públicos da União, bem como terrenos particulares;

b) Dar-se de forma gratuita ou onerosa;

c) Por prazo certo ou indeterminado;

d) Possuir finalidade específica de regularização fundiária de interesse social, de urbanização, e industrialização, de edificação, de cultivo da terra, de aproveitamento sustentável, de preservação das comunidades, seus meios de subsistência, bem como outras finalidades de interesse social em áreas urbanas. 
Aqui, diferentemente da concessão de uso especial para fins de moradia, admite-se outras finalidade de interesse social como, por exemplo, saúde, educação, cultura, assistência social, e ainda, de naturezas recreativas, esportivas e religiosas.

Podemos dizer que a concessão de direito real de uso é admitida em prol da pessoa jurídica, seja de direito público ou de direito privado.

Para tornar-se concessionário dessa modalidade é necessário o registro no Cartório de Registro de Imóveis, como determina os artigos 167, I e 40 da Lei $n^{\circ} 6.015 / 73$, Lei de Registro Público.

Por fim, com relação ao seu procedimento, aplica-se, no que couber, as mesmas regras da concessão de uso especial para fins de moradia.

\section{CONSIDERAÇÕES FINAIS}

Podemos dizer, que a Lei $\mathrm{n}^{\mathrm{o}} 11.481$ de 31 de maio de 2007 instituiu no ordenamento jurídico brasileiro a concessão de uso especial para fins de moradia e a concessão de direito real de uso que passaram a ser elencados no rol taxativo dos direitos reais previstos no artigo 1.225 do Código Civil.

Assim, a partir da análise detalhada dos novos direitos reais apresentados teve-se como ponto nodal a forma de efetivar o direito social à moradia e outros direitos sociais previstos na nossa Carta Maior.

A Constituição da República de 1988 consagrou o princípio da dignidade humana como conteúdo de todos os direitos fundamentais. Dentre os direitos fundamentais encontramos o acesso à moradia e direitos como a saúde, o lazer, a previdência e a segurança.

Portanto, podemos dizer que os novos direitos reais são instrumentos de concretização dos direitos fundamentais sociais, a partir do momento que garantem à população de baixa renda que se enquadra nos requisitos previstos em lei, o acesso a estes direitos ainda que instituídos em imóveis públicos.

A propriedade imóvel garantidora do direito à moradia é um bem escasso, principalmente em nosso país, onde a maioria da população almeja a aquisição da "tão sonhada casa própria”. Enquanto isso não é possível, o Estado busca ferramentas fundamentais aos cidadãos brasileiros para a realização de um local onde as pessoas possam exercer o mínimo necessário à vida digna: um lugar para morar.

Aliás, o direito de propriedade é o direito real mais amplo previsto no artigo 1.225 do Código Civil, e não por acaso possui disciplina sistematizada no nosso ordenamento jurídico. 
Neste sentido, a propriedade ganhou status de direito fundamental na Constituição desde que cumpra sua função social; e uma das formas do seu cumprimento está o exercício do bem condicionado à moradia da pessoa ou de sua família.

O direito real de habitação, outro direito real previsto no Código Civil também garante o direito à moradia de forma gratuita em imóveis particulares.

A questão interesse que analisamos com a promulgação da Lei $\mathrm{n}^{\circ} 11.481$ de 31 de maio de 2007 que na verdade veio disciplinar a Medida Provisória n 2.220 de 04 de setembro de 2001 foi a instituição de direito real, pela primeira vez, em bens públicos, ainda que para isto as pessoas tenham que preencher determinados requisitos.

A limitação a bens públicos encontra justificativa na medida em que busca efetivar princípios constitucionais concretizadores da dignidade humana, da solidariedade e da função social da propriedade.

Afinal, o problema do déficit habitacional não diz respeito somente aquele ou aquela família que não possuem um local de realização de suas satisfações diárias, mas trata-se de um problema que envolve a sociedade de forma geral.

\begin{abstract}
This work intends to study the new real rights introduced by the Brazilian Law $n^{\circ} 11,481$ of May 31, 2007 that modified article 1,225 of the Brazilian Civil Code and that are the special concession of use for housing purposes and the concession of the real right to use, which are institutes that aim towards the concretization of fundamental rights present in our Constitution. This paper first analyses the definition of a minimum content of the right to housing in association with the question of human dignity. Next, the paper studies these new real rights, considering its relationship with the importance of fundamental rights. By the analysis of the main characteristics of these new institutes, evokes an instrument that permits the effectiveness of the right to housing and of other fundamental rights that are the basis of the construction of democracy in our country.
\end{abstract}

Key-words: Fundamental rights; Human dignity; Concession of use for housing purposes; The concession of the real right to use.

\title{
REFERÊNCIAS
}

ALMEIDA, Guilherme Assis de; PERRONE-MOISÉS, Cláudia. Direito internacional dos direitos humanos: instrumentos básicos. São Paulo: Atlas, 2002.

BRASIL. Decreto-lei no 271, de 28 de fevereiro de 1967. Dispõe sobre loteamento urbano, responsabilidade do Ioteador concessão de uso e espaço aéreo e dá outras providências. DOU, Brasília, 28 fev. 1967. Disponível em: <http://www.planalto.gov.br/civil/DecretoLei/Del0271.htm>. Acesso em: 11 abr. 2009.

Revista da Faculdade Mineira de Direito, v.13, n. 25, jan./jun. 2010 - ISSN 1808-9429. 91 
Lei $\mathbf{n}^{\circ}$ 11.481, de 31 de maio de 2007. Dá nova redação aos dispositivos das Leis nos 9.636, de 15 de maio de 1998, 8.666, de 21 de junho de 1993, 11.124, de 16 de junho de 2005, 10.406, de 10 de janeiro de 2002 - Código Civil, 9.514, de 20 de novembro de 1997, e 6.015, de 31 de dezembro de 1973, e dos Decretos-Leis nos 9.760, de 5 de setembro de 1946, 271, de 28 de fevereiro de 1967, 1.876, de 15 de julho de 1981, e 2.398, de 21 de dezembro de 1987; prevê medidas voltadas à regularização fundiária de interesse social em imóveis da União; e dá outras providências. DOU, Brasília, 31 maio 2007. Edição extra. Disponível em: <http:// www.jusbrasil.com.br/legislacao/94733/lei-11481-07>. Acesso em: 05 fev. 2009.

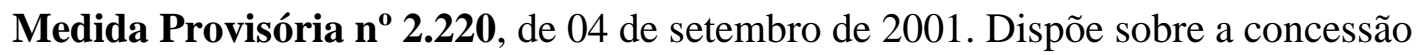
de uso especial de que trata o $\S 1^{\circ}$ do art. 183 da Constituição, cria o Conselho Nacional de Desenvolvimento Urbano - CNDU e dá outras providências. DOU, Brasília, 05 set. 2001. edição extra. Disponível em: <http://www.planalto.gov.br/ccivil_03/mpv/2220.htm>. Acesso em: 05 fev. 2009.

Novo código civil brasileiro (Lei $\mathbf{n}^{\mathbf{0}} \mathbf{1 0 . 4 0 6}$, de 10 de janeiro de 2002). 14. ed. atual. até 19.12.2008. São Paulo: Revista dos Tribunais, 2009.

DI PIETRO, Maria Silva Zanella. Direito administrativo. 18. ed. São Paulo: Atlas, 2005.

FACHIN, Luiz Edson. A função social da posse e a propriedade contemporânea: uma perspectiva da usucapião imobiliária rural. Porto Alegre: S. A. Fabris, 1988.

Estatuto jurídico do patrimônio mínimo. Rio de Janeiro: Renovar, 2001.

FARIAS, Cristiano Chaves de; ROSENVALD, Nelson. Direito reais. 3. ed. Rio de Janeiro: Lumen Juris, 2006

GOMES, Orlando. Direitos reais. 19. ed. rev., atual. e aum. por Luiz Edson Fachin. Rio de Janeiro: Forense, 2004.

MATHIAS, Maria Ligia Coelho; DANELUZZI, Maria Helena Marques Braceiro.

Considerações sobre a Lei n. 11.481/07: concessão de uso especial para fins de moradia e concessão de direito real de uso. Opus Justitiae, v. 197, p. 193-197, 2008.

MENDONÇA, Andrey Borges de; FERREIRA, Olavo Augusto Vianna Alves. Eficácia dos direitos fundamentais nas relações privadas. In: CAMARGO, Marcelo Novelino (Org.). Leituras complementares de direito constitucional: direitos fundamentais. 2. ed. Salvador: JusPodivm, 2007. p. 137-155.

MUKAI, Sylvio Toshiro. Direito à moradia e a concessão especial para fins de moradia. Fórum de Direito Urbano e Ambiental - FDUA, Belo Horizonte, ano 7, n. 38, p. 79-82, mar./abr. 2008.

NERY JÚNIOR, Nelson; NERY, Rosa Maria Andrade. Código civil comentado. 46. ed. rev., ampl. E atual. São Paulo: Revista dos Tribunais, 2008.

PENTEADO, Luciano de Camargo. Direito das coisas. São Paulo: Revista dos Tribunais, 2008.

RIZZARDO, Arnaldo. Direito das coisas. 3. ed. rev. e atual. Rio de Janeiro: Forense, 2007.

Revista da Faculdade Mineira de Direito, v.13, n. 25, jan./jun. 2010 - ISSN 1808-9429. 92 
SILVA, José Afonso da. Comentário contextual à constituição. 2. ed. de acordo com a EC 52. São Paulo: Malheiros, 2006.

Curso de direito constitucional positivo. 31. ed. São Paulo: Malheiros, 2008.

SOUZA, Adriano Stanley Rocha. Da autonomia privada nas situações jurídicas

patrimoniais e existenciais. Princípio da autonomia privada x princípio do numerus clausus em sede de direitos reais: um breve estudo de sua adequação à constituição brasileira de 1988 . In: FIÚZA, César; SÁ, Maria de Fátima Freire de; NAVES, Bruno Torquato de Oliveira (Coord.). Direito civil: atualidades II. Belo Horizonte: Del Rey, 2007. p. 211-227.

Direito das coisas. Belo Horizonte, Del Rey, 2009. v. VI, Coleção de Direito Civil.

Do direito de propriedade ao dever da propriedade. CONGRESSO NACIONAL DO CONPEDI, XVI. Anais ... Florianópolis: Fundação Boiteux, 2008. CD-Rom, p. 25812592. 